\title{
La institucionalización y profesionalización de la sociología en Brasil y Argentina. Formación, organización e intervención de los sociólogos*
}

\author{
Juan Pedro Blois \\ Universidad de Buenos Aires, \\ Universidad Nacional de General Sarmiento \\ pedro.blois@gmail.com
}

\section{Resumen}

En las últimas décadas los espacios laborales de los sociólogos en Brasil y Argentina tuvieron un notable crecimiento. El abanico de actividades y tareas fue ciertamente amplio, así como las esferas donde estos profesionales desembarcaron. Estos cambios supusieron una redefinición profunda del escenario de la sociología, con un número creciente de individuos trabajando en diversas instituciones o esferas sociales. Este artículo analiza los procesos de diferenciación profesional de la sociología en Brasil y Argentina en una perspectiva comparada. Contra lo que se podría esperar dadas las distintas trayectorias históricas de la disciplina en cada país, el modo en que los sociólogos se desempeñan en los diversos escenarios presenta fuertes convergencias, signadas por el predominio de una forma de concebir la disciplina que rechaza su desarrollo como una profesión de consulta.

Palabras clave: sociología, institucionalización, profesión, Brasil, Argentina.

* Nota de agradecimiento: algunas de las ideas presentadas en este artículo fueron examinadas en el seminario de discusión interna del Núcleo de Estudos de Teoria Social e América Latina (NETSAL) del IESP-UERJ coordinados por los profesores José Maurício Domingues y Breno Bringel, y en el grupo sobre Pensamento Social Brasileiro coordinado por el profesor André Botelho en el IFCS-UFRJ. Agradezco también los generosos comentarios y sugerencias de Pablo Bonaldi, José Maurício Domingues y Mariana Gené, así como los juicios, pistas y observaciones de los evaluadores de la revista que permitieron mejorar el argumento que aquí se desarrolla. 


\section{Abstract}

\section{The institutionalization and professionalization of sociology in Brazil and Argentina. Formation, organization and intervention of sociologists}

in the last decades, the professional insertions of sociologists in Brazil and Argentina had a remarkable growth. The variety of activities and tasks was certainly wide as the spheres where these professionals were incorporated. Those changes implied a deep redefinition of the sociology scenery, with an increasing number of sociologists working in diverse institutions and social spheres. This article analyses the process of professional differentiation of sociology in Brazil and Argentina in a comparative perspective. Against what could be expected given the different historical trajectories of the discipline in each country, the way in which the sociologists work in the diverse spheres presents strong convergences, characterized by the dominance of a conception of the discipline that rejects the development of sociology as a consulting profession.

Key words: sociology, institutionalization, profession, Brazil, Argentina.

\section{Introducción}

Actualmente, cuando un joven sociólogo brasileño o argentino ingresa al mercado laboral se abre frente a él un amplio abanico de opciones donde insertarse. Aun cuando no siempre tenga pleno conocimiento de esas posibilidades o acceso a las mismas, el trabajo como sociólogo no implica ya de modo necesario o mayoritario una inserción en el mundo académico, como docente o investigador. Si esa inserción se mantiene como la más visible y reconocida (en particular en los espacios de formación universitarios), desde hace varios años, un conjunto variado de instituciones no académicas han venido incorporando de manera creciente una buena parte de los graduados que año con año se incorporan al mundo del trabajo. Dependencias estatales, consultoras de opinión pública y análisis de mercado, grandes empresas privadas, ONG e incluso organismos internacionales, se han ido consolidando en ambos países como campos o espacios de intervención de los sociólogos (Braga, 2011; Rubinich y Beltrán, 2010). ${ }^{1}$

${ }^{1}$ En el caso de Brasil se considera como sociólogo al individuo que posee diploma universitario en "Ciencias Sociales"; a diferencia de lo que ocurre en Argentina, donde ya desde la formación de grado la sociología se halla constituida como carrera particular, la diferenciación entre esa disciplina y las otras ciencias sociales (la antropología y la ciencia política) se da por lo general a partir del nivel de maestría. En este trabajo, siguiendo lo realizado por los investigadores brasileños que han estudiado el desarrollo de las prácticas profesionales de la 
El espectro de actividades desarrolladas por los sociólogos es, en este marco, muy amplio y demanda diversas habilidades o destrezas. Desde la producción, sistematización y análisis de distintos tipos de información, tarea en la cual el instrumental metodológico propio de la disciplina es profusamente utilizado, hasta las actividades de gestión y planificación en diversas instituciones, pasando por las tareas de intervención directa con diversas poblaciones y grupos sociales. En este sentido, a diferencia de otros perfiles profesionales, los sociólogos mostraron una notable versatilidad y una gran capacidad para penetrar en diversos campos de intervención. Sin duda, esos cambios expresan las transformaciones más generales de la sociedad brasileña y argentina en el contexto de la denominada "sociedad del conocimiento", signada por una creciente valoración del saber técnico (Dubet, 2012).

Aun cuando no se tratara de un hecho sin precedentes (Bonelli, 1993), lo anterior supuso una redefinición profunda del escenario de la sociología en Brasil y Argentina, marcado por el ascenso de un conjunto variado de prácticas profesionales diferenciadas: al "trabajo académico", que se consolidó y expandió en el marco de un sostenido proceso de "profesionalización" (más vigoroso y extendido en Brasil pero visible también en Argentina), se le sumaron la "consultoría para ONG", el "trabajo en el Estado", la "investigación de mercado" y el "análisis de opinión", entre otras. ${ }^{2}$

El presente artículo analiza los procesos de diferenciación profesional de la sociología en Brasil y Argentina en una perspectiva comparada. La

sociología, serán comprendidos los sociólogos que actúan en diferentes áreas que tengan como base la formación de "cientista social". Para una reflexión sobre la relación de la sociología con las otras ciencias sociales en Brasil y Argentina en el momento de su fundación, puede verse Jackson y Blanco (2014).

${ }^{2}$ Tanto en Brasil como en Argentina, los estudios cuantitativos sobre las prácticas profesionales de los sociólogos y sus diversos escenarios de acción no son muy numerosos. En el primer caso contamos con los datos ofrecidos por diversas investigaciones que, sin embargo, estuvieron acotadas al estudio de ciertas poblaciones (como los graduados de alguna carrera en particular o los habitantes de algún estado) sin pretensiones de elaborar un estudio representativo de la realidad nacional (entre otros, Braga, 2011; Bonelli, 1993; Schwartzman, 1995; Steren dos Santos y Barreto, 2010). En Argentina, el panorama es más incipiente pues sólo contamos con los estudios realizados por el Laboratorio de Análisis Ocupacional de la FCS de la UBA (1991 y 2001) y una encuesta de fines de los años noventa (Rubinich y Beltrán, 2010). Ahora bien, más allá de las discrepancias en la forma de clasificar y construir la información empírica que presentan esas indagaciones (rasgo que las vuelve incomparables), todas apuntan en un mismo sentido: aun cuando la práctica académica persiste como un núcleo relevante, ocupando por lo general a un cuarto de los graduados (en actividades de investigación y docencia), las otras prácticas, ciertamente muy diversas, son mayoría. Por supuesto, la expansión del mercado laboral de los sociólogos no constituye una particularidad del caso brasileño o argentino. Para el caso francés, puede verse Piriou (2006). Sobre Estados Unidos, Burawoy (2005). Para México, entre otros, Machuca (2008), Mejía (2008), y Reinaga Obregón (1998). 
pregunta que lo orienta es cómo se relacionaron los procesos históricos de conformación e institucionalización de la disciplina en cada país con la constitución de las prácticas laborales de los sociólogos. Según entendemos, la historia de una disciplina no es un pasado muerto, algo que simplemente pasó y que ya no tiene incidencia alguna. Por el contrario, las diversas tradiciones y modos de pensar la práctica de los sociólogos, configurados a lo largo del tiempo y apoyados en procesos históricos de más larga data, sedimentados en instituciones, culturas e ideales particulares, resultan fundamentales para entender el presente de las prácticas profesionales de la disciplina.

En primer lugar se reconstruirán algunos rasgos de la trayectoria de la disciplina en Brasil y Argentina, procurando ilustrar sus diferencias. A continuación se realizará el análisis de las prácticas profesionales de los sociólogos de acuerdo con una serie de ejes (la vinculación entre espacios de formación y mundo del trabajo, el papel de las asociaciones profesionales, la vinculación con los clientes y esferas de acción). Se buscará, luego, dar cuenta de las semejanzas encontradas considerando el predominio de una tradición o "cultura" sociológica "crítica" que, en ambos casos, deslegitimó la conformación de la sociología como una profesión de consulta (Freidson, 2009). ${ }^{3}$

\section{La trayectoria histórica de la sociología en Brasil y Argentina}

Cuando se consideran en clave comparada las trayectorias de la sociología en Brasil y Argentina saltan a la vista fuertes diferencias. Si bien es posible reconocer ciertas afinidades, lo cierto es que los esfuerzos por institucionalizar y legitimar la disciplina realizados en ambos países tuvieron suertes diferentes. Mientras que en Argentina el desarrollo de la sociología aparece signado por una sucesión accidentada de etapas, muy divergentes entre sí; en Brasil, en contraste, su devenir está marcado por una relativa estabilidad y un recorrido en el que, aun cuando no falten los momentos de crisis y reorientación profundos, resaltan las continuidades sobre las rupturas. ${ }^{4}$

\footnotetext{
${ }^{3}$ Para el caso argentino, el análisis está basado en el trabajo desarrollado para mi investigación de doctorado (Blois, 2012). Esa investigación estuvo basada en el análisis de un amplio corpus empírico: documentos y memorias institucionales, publicaciones de estudiantes y sociólogos, entrevistas a actores relevantes en la historia de la disciplina, estadísticas sobre espacios de formación y salidas laborales, entrevistas en profundidad a una muestra de graduados con el fin de reconstruir trayectorias profesionales. Para el caso brasileño, el análisis se sustenta en una serie de investigaciones disponibles sobre la sociología en ese país, entrevistas a sociólogos, informantes clave e investigadores especializados, y también en fuentes secundarias y documentales.

${ }^{4}$ Para un análisis comparado de las trayectorias históricas de la sociología en Brasil y
} 
En Argentina la trayectoria de la sociología se caracterizó por una fuerte inestabilidad, con momentos de quiebre que, en varios casos, demarcaron periodos que se pretendían "refundacionales" (Pereyra, 2007; Rubinich, 1999). Esa inestabilidad estuvo asociada a la inexistencia de un acuerdo sobre lo que debía ser la disciplina. Antes bien, los límites, las formas de trabajo y el propio sentido de la sociología fueron siempre objeto de álgidas luchas y disputas (Blois, 2008). Si para algunos como Gino Germani - fundador de la primera carrera en el país - la sociología era una disciplina científica que, aun cuando estuviese motivada por dar respuestas a las necesidades urgentes de su sociedad, debía distinguirse del discurso ideológico y político, para otros la idea de profesión no concitaba ningún interés y aparecía como una coartada que, con base en una falsa neutralidad, ponía al sociólogo a favor del manteniendo del orden vigente y al servicio de los poderosos (Verón, 1974). Las disputas fueron tales que resultó posible hablar de "sociologías" en plural, estilos o grupos que no se reconocían como interlocutores válidos (Delich, 1977).

Pero las rupturas y reorientaciones experimentadas por la sociología en Argentina no fueron solamente consecuencia de las diferencias entre los propios sociólogos. Lejos de ello, esas rupturas estuvieron fuertemente condicionadas por las sucesivas crisis políticas y sociales que sacudieron la vida del país. Incapaz de mantenerse al margen de la inestabilidad que signó el periodo posterior a la experiencia peronista (1945-1955), los recambios en las autoridades gubernamentales coincidieron por lo general con renovaciones profundas del plantel docente. Sólo a partir de la vuelta de la democracia a mediados de los años ochenta se inaugura un periodo de estabilidad que, en buena medida, se extiende hasta nuestros días (Kreimer y Blanco, 2008).

En comparación, el derrotero de la sociología en Brasil aparece marcado por la progresiva institucionalización. En efecto, desde mediados de los años treinta, momento en el que las ciencias sociales desembarcan en la academia como carrera universitaria, la sociología tendió a consolidar y expandir su presencia en las instituciones de educación superior y en las agencias de fomento científico. En ese sentido, entre quienes se han dedicado a estudiar el derrotero de la disciplina existe un marcado consenso en torno al "éxito" de su institucionalización. Sea que se refiera la cantidad de carreras de grado y cursos de posgrado, sea que se mencione la proliferación de revistas especializadas, sea que se destaque la apreciable porción de financiamiento que le acuerdan las instituciones de fomento científico, todos coinciden en señalar su consolidación y fortaleza (Miceli, 1995; Trindade, 2007).

Argentina, que aquí sólo podemos referir brevemente, puede verse Blois (2013a), Jackson y Blanco (2014), y Liedke Filho (1990). 
Por supuesto, eso no quiere decir que no haya habido fuertes divergencias a la hora de concebir el papel de la sociología y el rol del sociólogo en la sociedad. Cabe recordar aquí las marcadas diferencias entre los estilos sociológicos que caracterizaron los dos polos intelectuales más importantes del país: Sao Paulo y Rio de Janeiro. Mientras que en el primero predominó un ejercicio más autocentrado de la sociología representado de manera arquetípica por los sociólogos de la USP; en Rio de Janeiro se afirmó, en contrapartida, una definida vocación por la intervención política e ideológica directa - expresada de manera patente en el Instituto Superior de Estudos Brasileiros (ISEB) - (Jackson y Blanco, 2014; Keinert, 2010; Lippi, 1995; Miceli, 1995; Vianna, 2004). Ahora bien, a diferencia de lo ocurrido en Argentina, semejantes diferencias no impidieron el diálogo e intercambio entre quienes adherían a uno y otro estilos. ${ }^{5} \mathrm{Si}$ no faltaron las críticas agudas y los argumentos filosos, el hecho mismo de la polémica demuestra el reconocimiento del otro como miembro de una misma comunidad disciplinaria.

Los derroteros de la sociología en Brasil y Argentina no pueden estar desvinculados de las particulares relaciones que la disciplina tejió en cada caso con el Estado. En Brasil, aun cuando ese vínculo no estuvo exento de fuertes tensiones y conflictos, los sociólogos, en momentos y coyunturas sociales y políticas ciertamente diferentes, pudieron aprovechar la receptividad que, bajo diversas modalidades, esa institución tuvo hacia la disciplina y legitimar de ese modo la pertinencia de sus labores. Si ello pudo asegurar un significativo apoyo material para la disciplina, produjo también una amplia expectativa sobre su papel o rol en la resolución de los problemas y desafíos que el Estado, y quienes lo controlaban, reconocían como más apremiantes (Carvalho, 2007).

Esa vinculación se inscribía en la relación más amplia entre intelectuales y élites políticas que, desde la propia constitución del Estado brasileño había dado un marcado protagonismo a la ciencia y al saber especializado — como sea que se lo definiera - a la hora de orientar las iniciativas políticas y los horizontes de acción. Desde entonces y durante buena parte del siglo XX se dio un proceso de mutuo reforzamiento: mientras que las élites buscaban en el discurso y en hallazgos de los intelectuales un recurso capaz de fundamentar y legitimar sus iniciativas, los intelectuales (en sus más diversas orientacio-

${ }^{5}$ Cabe recordar aquí las prolongadas polémicas entre Florestan Fernandes, Roger Bastide, Luis Costa Pinto y Alberto Guerreiro Ramos, pero también la participación de esos sociólogos en empresas de investigación conjuntas, o su convivencia en una misma asociación profesional (como la Sociedade Brasileira de Sociologia); realidad que contrasta con el caso argentino donde Germani, a fin de excluir a los "sociólogos de cátedra" promovió la creación de una nueva asociación profesional que, contra aquellos profesores, imponía como requisito tener una dedicación "exclusiva" a la disciplina (Blanco, 2006). 
nes), atendiendo esas demandas, procuraron constituirse como un grupo con la capacidad de intervenir activamente en la esfera pública "al servicio de la construcción política del país" (Pécaut, 1990). ${ }^{6}$

Lo anterior contrasta de manera marcada con lo ocurrido en Argentina, donde la vinculación entre intelectuales, élites y Estado fue ciertamente problemática, como lo expresan la relación conflictiva de las autoridades políticas con las universidades públicas y el paralelo florecimiento de circuitos intelectuales alternativos y en disputa con los oficiales. ${ }^{7}$ El vínculo no fue distinto con otras instituciones de la sociedad civil (como los sindicatos, las organizaciones empresarias o los partidos políticos mayoritarios), donde raramente los intelectuales pudieron incorporarse o ser reconocidos como voces de peso. Entre esas instituciones y los intelectuales tendió a predominar una persistente desconfianza (Sarlo, 2002). Los intelectuales, y entre ellos los propios sociólogos, tendieron a definir su intervención e identidad "en contra" del Estado. Éste, como contrapartida, tendió a ignorarlos.

Como muestra de lo anterior cabe recordar la forma en que se produce la institucionalización de la sociología y las ciencias sociales como cursos universitarios en cada país. En Brasil, su incorporación fue una iniciativa de las élites sociales y culturales (paulistas y cariocas) que buscaban, por esa vía, asegurar su liderazgo cultural y político a nivel nacional (Limongi, 1989). ${ }^{8} \mathrm{De}$ ahí su iniciativa para convocar a un conjunto de profesores e investigadores extranjeros como estrategia de importación de la nueva disciplina (Massi, 1989). Aun cuando posteriormente los espacios de formación redefinieran sus metas y reclamaran, al menos en Sao Paulo, una mayor autonomía frente a las orientaciones de sus mentores, el apoyo no mermó (Miceli, 1989).

No se trataba, en ese sentido - como ocurriría tiempo después en Argentina - de una empresa liderada por un "héroe modernizador" (Noé, 2005) sin demasiadas vinculaciones con las élites sociales y políticas, que debió conseguir buena parte de los recursos económicos que su empresa precisaba en un conjunto de instituciones extranjeras (Germani, 2004). Lo ocurrido en la Carrera de la UBA con el golpe de Estado de 1966 da cuenta de la debilidad de esos lazos. Sin mentores o protectores con llegada a las nuevas autorida-

\footnotetext{
${ }^{6}$ Sobre el rol de los intelectuales en la construcción de las identidades sociales y nacionales en una perspectiva más general y teórica, puede verse Domingues (2003).

${ }^{7}$ Como el Colegio Libre de Estudios Superiores durante el primer peronismo o los centros privados de estudio e investigación en los años sesenta y setenta. Cf. Blanco (2006), y Sábato (1996).

${ }^{8}$ Las instituciones pioneras fueron la Escuela Libre de Sociología y Política (ELSP) y la Universidad de Sao Paulo (USP), en Sao Paulo, y la Universidad del Distrito Federal (UDF), prontamente reemplazada por la Facultad Nacional de Filosofía (UNFi), en Rio de Janeiro.
} 
des militares, la mayoría de los docentes que Germani había formado debieron dejar sus cargos, siendo la carrera reorganizada sobre bases ciertamente distintas a las proyectadas por el sociólogo italiano (García Bouza y Verón, 1967).

Al analizar el impacto de los golpes de Estado sobre la disciplina, las diferencias en la relación de la sociología con el Estado son también marcadas. Frente al efecto fuertemente desarticulador experimentado durante la última dictadura militar en Argentina (1976-1983), el régimen impuesto en Brasil en 1964 inaugura, de modo ciertamente paradójico, un proceso de sostenida institucionalización y expansión (Miceli, 1995). El accionar de las autoridades combinó una definida intervención represiva ${ }^{9}$ con una política de expansión y "modernización" de las instituciones académicas y científicas sin precedentes (Ortiz, 1990). Aun cuando esa política inicialmente no tenía a la sociología o las ciencias sociales como destinatarias (sino a las ciencias naturales), terminó favoreciendo su desarrollo, visible en la fuerte ampliación del nivel de posgrado y los subsidios disponibles para investigación.

Mientras que los militares brasileños propiciaban la vinculación entre la docencia y la investigación, sus pares argentinos buscaron deliberadamente su divorcio. Para ello redujeron los presupuestos universitarios en favor de una serie de institutos de investigación dependientes del Estado pero ajenos a las universidades. Éstos, en su visión, debían concentrar sus esfuerzos en la labor docente (Bekerman, 2009). En ese marco, la carrera de la UBA, la principal del país, sufrió una fuerte intervención. Inicialmente clausurada, luego de considerarse la posibilidad de su cierre definitivo, fue reabierta en 1977 en condiciones irreconocibles. El número de estudiantes había decaído a una pequeña fracción y los profesores habían sido reemplazados prácticamente en su totalidad. Sus sucesores tenían una formación poco especializada: las diversas "sociologías" que se habían sucedido en el control de la institución desde su fundación - la "sociología científica", la "sociología nacional", la "sociología marxista"- fueron excluidas por igual (Raus, 2007; Sidicaro, 1993).

En ese marco cobraron importancia los denominados centros privados de investigación cuyas actividades ilustran, una vez más, las diferencias en los derroteros de la sociología en uno y otro países. Tales centros, tanto en Brasil como en Argentina, sirvieron de refugio para los sociólogos que habían sido separados de sus cargos por las autoridades militares y constituyeron espacios dinámicos en la renovación de las orientaciones y estilos de trabajo (Brunner

\footnotetext{
${ }^{9}$ Hubo cursos, como el de la USP y la UNFi, que sufrieron la dimisión de varios de sus profesores y la persecución de sus estudiantes.
} 
y Barrios, 1987). Contaron para ello con un significativo financiamiento externo. Ahora bien, los centros brasileros, fieles a la tradicional relación de los intelectuales con la política y el Estado, pudieron realizar una serie de investigaciones sobre la coyuntura política y social, y ganar, no sin resistencias, una marcada visibilidad pública. Tal visibilidad les dio un rol central en la oposición al régimen militar y en los debates alrededor del retorno a la democracia (Keinert, 2010; Lahuerta, 2001) ${ }^{10}$ Ese alto perfil contrastaba fuertemente con lo que ocurría con los centros privados en Argentina. Obligados a operar en la denominada "universidad de las catacumbas", dado el clima de cerrada censura y persecución, sus actividades permanecieron fuertemente "encapsuladas", más conectadas con las agendas y preocupaciones de quienes financiaban sus actividades desde el exterior que con problemáticas "calientes" del medio local (Sábato, 1996). Lo anterior es una muestra más de la relativa centralidad que la sociología ha tenido tradicionalmente en el campo intelectual y la esfera pública brasileña desde sus propios orígenes, tan contrastante con la situación argentina (Pécaut, 1990).

\section{Los sociólogos y el mundo del trabajo en Brasil y Argentina}

Según intentamos mostrar en la sección anterior, a partir del análisis de algunos rasgos o coyunturas relevantes, la sociología en Brasil y Argentina presenta trayectorias variadas, condicionadas por una relación distinta con el Estado y las élites políticas y sociales. Tales diferencias, sin embargo, no se expresan de manera tan palpable cuando se observa el modo en que los sociólogos se vinculan con el mundo del trabajo. Allí, contra lo que se podría esperar a partir de historias tan divergentes, los contrastes pierden fuerza en favor de las semejanzas. Para analizar las prácticas profesionales de los sociólogos en Brasil y Argentina, nos centraremos en los siguientes ejes: la relación entre las carreras y las prácticas de sus graduados; el rol de las asociaciones de profesionales; y finalmente la relación de los sociólogos con sus empleadores y esferas de acción.

${ }^{10}$ Cabe recordar aquí las relaciones que el Centro Brasileiro de Analise e Planejamento (CEBRAP) mantuvo con sectores de la Iglesia católica, institución de fuerte gravitación en la oposición y el cuestionamiento del régimen vigente, así como los vínculos que algunas de sus figuras entablaron con el naciente Movimiento Democrático Brasileiro. Del mismo modo, cabe mencionar las relaciones del Centro de Estudos de Cultura Contemporânea (CEDEC) con el movimiento obrero y la participación de algunos de sus intelectuales en la fundación del Partido dos Trabalhadores (PT) (Perlatto, 2013). 


\section{Los espacios de formación y las prácticas profesionales de los sociólogos}

Tanto en Brasil como en Argentina, las carreras universitarias tienen por lo general como finalidad más o menos explícita la formación de sociólogos dedicados a la vida académica (Alves, 2007; Andrade, 2002; Blois, 2009; Bonaldi, 2009; Gomes de Melo, 2005; Schwartzman, 1995; Braga, no publicado). Las tareas que aparecen como deseables son la docencia y la investigación. Frente a ese ideal, las otras opciones laborales son por lo general ignoradas (o bien subestimadas y desvalorizadas). Todas ellas (sea que se den en el mercado, en el sector público o en el denominado tercer sector) parecen estar por debajo de la figura del investigador docente. En Brasil, dada la difusión e institucionalización del sistema de posgrado, tal orientación resulta reforzada: para los docentes y buena parte de los alumnos la graduación aparece solamente como un paso previo necesario para acceder a la maestría (y luego al doctorado) (Leite, 2003).

Según han destacado diversos observadores brasileños, esa orientación es un producto del perfil de quienes tienen a su cargo la enseñanza. En un marco donde las dedicaciones exclusivas son moneda corriente, el estudiante es formado casi exclusivamente por personas que comparten sólo uno de los espacios de actividad: la docencia universitaria y la investigación académica (Braga, 2009; Miglievich, 1999). En esas condiciones,

es fácil pasarle una definición de sociólogo que tiende a una idea de trabajo intelectual muy impregnada de los modos, de las exigencias y recompensas de las jerarquías universitarias y de la cultura académica: presencia en simposios, congresos y conferencias, titulación y publicaciones. Es por medio de ella que la comunidad de sociólogos, centrada en ese modelo, distingue quién pertenece a ella y quién no. Los demás frentes de trabajo no son mencionados en las clases, manteniéndose en relación a ellos una actividad que va de la complacencia a la hostilidad, en nombre del militantismo político y/o del pensar teórico. (Durand, 1984: 76) $)^{11}$

Ahora bien, cabe señalar que la conformación de un plantel docente más heterogéneo no garantiza la conformación de un perfil de enseñanza más plural. En la carrera de la UBA las dedicaciones simples son mayoría de modo tal que buena parte de su plantel docente tiene como inserción principal (en términos de tiempo empleado e ingresos recibidos) una actividad no académica. Sin embargo, esos docentes, sin poner en cuestión la definición de la sociología como empresa eminentemente académica que domina la institu-

\footnotetext{
${ }^{11}$ Cuando la referencia al texto citado no es en español la traducción es propia.
} 
ción, no refieren en sus clases esas actividades, contribuyendo a la invisibilización de sus propias prácticas como sociólogos más allá de los muros universitarios (Blois, 2009). ${ }^{12}$

De esa manera, tanto en Brasil como en Argentina, los espacios de formación tienden a plantear un fuerte clivaje entre el ejercicio académico y no académico de la disciplina. En la medida en que no se incorporan las experiencias que los sociólogos desarrollan más allá de los muros universitarios, se opera como si no todas las inserciones laborales a las que es posible acceder con un título de sociólogo fueran verdaderamente constitutivas de la disciplina. Así, los futuros graduados aprenden a distinguir entre sociólogos "de primera", aquellos insertos en la academia, y sociólogos "de segunda", aquellos empleados en distintas instituciones no académicas. Quienes no quieran o no puedan insertarse en el medio académico deberán lidiar con la sensación de poner en juego una práctica cuyo estatus "sociológico" o pertenencia a la disciplina está ciertamente en duda (Blois, 2013a; Braga, 2009).

\section{¿La sociología como profesión? Las asociaciones profesionales de sociólogos}

Tanto en Brasil como en Argentina, las entidades que buscaron representar a los sociólogos según el modelo de las profesiones tradicionales estuvieron marcadas por una profunda debilidad, falta de reconocimiento y marginalidad en el campo. Si, por un lado, lograron la promulgación de una ley nacional de regulación del ejercicio de la profesión, que exige el registro de todo aquel sociólogo que se desempeñe profesionalmente, por el otro, los vaivenes en el número de matriculados, así como el hecho de que sea común dar con sociólogos que desconocen la existencia de esas instituciones (Blois, 2012; Torini, 2012), revelan el rol limitado que sus esfuerzos han podido ejercer en la estructuración del mercado laboral.

En Brasil, la campaña por la regulación de la sociología como profesión inició a comienzos de los años sesenta. En torno a tal iniciativa, según señala Marinho, se suscitaban dos posiciones. Por una parte, estaba aquella "compuesta por sociólogos de alta calificación dedicados a la investigación en sociología como disciplina académica" para la cual no tenía sentido proponerse esa regulación. Por otro lado, estaba aquella "integrada, en su gran mayoría,

${ }^{12}$ Preciso es aclarar que la prescindencia de los espacios de formación en relación con el futuro laboral coincide en buena medida con las expectativas de quienes deciden estudiar sociología o ciencias sociales, más preocupados por desarrollar una vocación intelectual o política que por proyectar, al menos inicialmente, una carrera profesional (Alves, 2007; Bonaldi, 2009). 
por sociólogos de menor calificación académica [empleados] preponderantemente, en diversos órganos de la administración pública [que defendían] como justa y necesaria la causa de la regulación" (Marinho, 1987: 227). Fruto de los esfuerzos de estos últimos surgieron en diversos estados asociaciones que buscaron afiliar y representar a los sociólogos con inserciones no académicas. Esas asociaciones se organizaron a nivel nacional en 1977 en la Associação de Sociólogos do Brasil. Sin embargo, estuvieron siempre sujetas a una fuerte inestabilidad - los periodos de actividad y relativa visibilidad se sucedieron con momentos de virtual inactividad-, careciendo de conexiones firmes con los espacios de formación (Carvalho y Mattos, 2005).

Tal debilidad contrasta con la fuerza de la Sociedade Brasileira de Sociologia (SBS), organización de claro perfil académico fundada en 1950 y recuperada, luego del impasse introducido por la última dictadura militar, a mediados de los años ochenta (Barreira, 2003). Esa institución ha sido central, junto con otras instituciones como la Associação Nacional de Pós-Graduação e Pesquisa em Ciências Sociais (ANPOCS), a la hora de negociar los contenidos de las políticas y el monto de los recursos asignados por las burocracias estatales vinculadas al área de educación superior y ciencia (Blundi, 1997; Miceli, 1995). ${ }^{13}$ En ese sentido, si difícilmente pueda hablarse de una profesión de sociólogo constituido según el modelo de las profesiones clásicas, Marinho no duda en señalar el éxito de los "sociólogos académicos" como "profesionales" a la hora de monopolizar ciertas posiciones y recursos, tan contrastante con "las dificultades del sociólogo que busca una inserción profesional en el mercado de trabajo más amplio" (Miglievich, 1999: 35).

Surgido en 1975, el Colegio de Graduados de Sociología (CGS) de la Ciudad de Buenos Aires se constituyó como un espacio de reunión de varios de los sociólogos que habían sido expulsados de la carrera de la UBA a partir de la intervención militar. Esta institución mantuvo cierto dinamismo durante los primeros años de la vuelta de la democracia, teniendo un rol destacado en la formulación de un primer - y fallido - plan de estudios para esa carrera. ${ }^{14}$ Su sucesor, el Consejo de Profesionales de Sociología, no pudo, sin embargo, mantener aquel lugar y permaneció como una institución poco gravitante (Blois, 2009).

${ }^{13} \mathrm{Tal}$ sociedad no tiene equivalente en Argentina. Si bien hubo algunos antecedentes, aquellas iniciativas no pudieron sostenerse a lo largo del tiempo. Cf. Blanco (2006).

${ }^{14}$ Ese plan tenía, en relación con planes anteriores, una particularidad: fijaba como requisito para la obtención del diploma la realización de una práctica preprofesional fuera del ámbito académico. El plan fue, sin embargo, resistido por los estudiantes, siendo reemplazado en 1988 por otro donde aquella pasantía — que sin duda hubiera alentado un perfil de formación distinto - había sido eliminada (Blois, 2012). 


\section{Los sociólogos y sus esferas laborales}

La forma en que los sociólogos desarrollan sus actividades cuando se insertan en una esfera o institución no académica está fuertemente condicionada por la lógica de esos espacios. Por sus objetivos y dimensiones, esas instituciones presentan importantes diferencias: persiguen orientaciones específicas, tienen un tamaño y alcance dispares, exigen tareas y ritmos de trabajo diferenciados, poseen formas de ingreso y jerarquías particulares. Al demandar distintas tareas y saberes, esas esferas promueven la multiplicación de un conjunto diferenciado de prácticas u "oficios" de sociólogo. Ahora bien, ¿cómo se posicionan los sociólogos en Brasil y Argentina frente a esas demandas?

Cuando se observan las prácticas laborales de los sociólogos empleados fuera de la academia no es extraño encontrar que su trabajo está signado por una profunda debilidad frente a los pedidos o demandas de sus clientes o empleadores. Aun cuando puedan experimentar cierto malestar ante tal situación, deben por lo general trabajar según los plazos, el rigor y el nivel de elaboración o profundidad definidos por quienes los contratan. Según la esfera de la que se trate (el Estado, las empresas, las ONG) los imperativos pueden variar, pero en general tiende a predominar una misma adaptación. Para ilustrar lo anterior tomemos la situación de los sociólogos especializados en análisis de mercado. ${ }^{15}$

En este caso, por supuesto, las necesidades del cliente - en la medida en que financia el trabajo - son un elemento a tener en cuenta. De hecho, hay veces que a la consultora llega un pedido estrictamente delimitado que indica lo que hay que hacer (estrategia y técnicas metodológicas a emplear, tamaño de la muestra, cantidad de entrevistas a realizar, etc.), pero también hay oportunidades en las que lo que se encarga es más difuso y permite poner en juego una labor más creativa. Ahora bien, para quienes se insertan en el sector privado el mayor condicionamiento es, sin duda, la necesidad de vender. Ella siempre aparece como un límite a lo que se puede investigar, hacer o decir, pudiendo demandar a veces el abandono de las propias convicciones sobre la mejor forma de hacer el estudio. En esas condiciones, según reconocen los propios graduados, antes que la realización de un estudio "serio" o "bien hecho", lo importante en una buena proporción de casos es ofrecer argumentos susceptibles de legitimar o justificar decisiones previamente tomadas. Tal tendencia era criticada por Durand para quien los investigadores de mercado terminaban siendo "dócilmente limitados a lo que el cliente postula":

\footnotetext{
${ }^{15}$ Para un análisis más amplio y detallado que incluye las inserciones en otras esferas, puede verse Blois (2013a).
} 
Empleados en jornadas de tiempo completo acaban sucumbiendo al ritmo agitado de los plazos de entrega de los informes y a la disputa por los clientes más dispendiosos. De ahí resulta tal complicidad con el medio gerencial que difícilmente se encuentre algún investigador de mercado que tenga preguntas propias para los públicos que entrevista [...] Aun cuando consiguen diseñar alguna investigación que dé más curso a la imaginación y revele alguna dimensión desconocida de la sociedad, no están estimulados para retrabajar los resultados fuera del medio y fuera del discurso impuesto por el medio. (Durand, 1984: 77, 78)

Si ello puede incomodar, pues estos sociólogos no dejan de sentir que lo que hacen carece de valor desde el punto de vista disciplinario, lo cierto es que esta situación tiene un costado "liberador", ya que exime de la necesidad de pensar, para cada uno de sus encargos, las condiciones en las que su trabajo debería ser realizado en vistas a garantizar su rigor o precisión. En lugar de ello, y evitando cualquier negociación que podría tensar la relación con quienes suministran los recursos, los sociólogos ofrecen lo que el cliente o empleador demanda (y cree necesitar) para sus preocupaciones más inmediatas. Ello, por supuesto, no necesariamente coincide con aquello que podría surgir de un estudio más sistemático. En estos casos, la tensión propia de cualquier profesión entre el interés comercial (la necesidad de vender un servicio) y la ética profesional (la necesidad de proveerlo con base en ciertos estándares de calidad cognitivos y éticos), se diluye. En esas condiciones, como afirma Braga, "es el mercado el que nivela la profesión [de modo tal que] son los atributos valorizados por el mercado - la respuesta rápida, la información sin pensamiento, el foco en el cliente - que dictan la configuración del sector y de las habilidades exigidas" (Braga, 2009: 165).

Frente a las actividades no académicas, la sociología practicada en los espacios universitarios aparece como el ámbito donde se puede gozar de una amplia autonomía frente a las audiencias o públicos más amplios. Tal situación, en efecto, puede vincularse con el proceso de consolidación del sistema científico que, desde hace varios años fue, tanto en Brasil como en Argentina, generando un entramado institucional que premió de manera creciente aquellas iniciativas vinculadas a la producción destinada a los propios pares (la publicación de artículos, la participación en congresos, etc.) en detrimento de aquella volcada hacia "fuera" (la divulgación, la transferencia, etcétera). Si ello reforzó los grados de autonomía, conllevó también una cuota correlativa de "ensimismamiento" de la esfera académica (Perlatto, 2010; Unzué, 2013).

En ese marco, si bien hay importantes excepciones, ${ }^{16}$ no es inusual que para buena parte de los académicos sus audiencias o públicos se reduzcan a

${ }^{16}$ Hay, en efecto, casos en que los académicos trabajan para algún órgano de gobierno 
sus estudiantes y colegas. Mientras que algunos viven con incomodidad lo que consideran un excesivo "encierro" y anhelan la posibilidad de generar vínculos con actores o instituciones no académicos, otros asumen con naturalidad ese estado de cosas y se acomodan a las exigencias propias del sistema académico.

Contra tal "aislamiento" de los académicos (o "autopoiesis", según el testimonio irónico de uno de los representantes del Sindicato dos Sociólogos do Estado do Rio de Janeiro), y como una forma de jerarquizar sus propias prácticas, los sociólogos con inserciones no académicas suelen resaltar las relaciones de cercanía que tienen con quienes toman decisiones en las diversas esferas donde actúan. Su labor, según gustan señalar, no termina en una pura discusión de colegas, "aislada" del conjunto de la sociedad. Su sociología es una sociología "conectada" (Blois, 2013b; Braga, 2009).

De ese modo, estos sociólogos disputan el sentido o "para qué" de la disciplina. Pese a que reconocen que la demanda condiciona y puede ser perniciosa, como cuando los ritmos exigidos en su trabajo no les dan la posibilidad de realizar estudios más fundados o rigurosos, no dejan de atribuirle un efecto beneficioso: evitar la tendencia que, según ellos, caracteriza a la sociología académica al "encierro", y ofrecer siempre a sus labores una justificación o relevancia ostensible en los usos que los clientes y audiencias profanas realizan de sus servicios. Si no pueden reivindicar la autonomía pues la consideran poco factible en sus espacios laborales, los graduados con inserciones no académicas exaltan la idea de intervención social para jerarquizar su trabajo (y recusar el de sus pares académicos). En esas condiciones, tienden a configurarse dos oficios claramente diferenciados: un oficio académico autónomo pero crecientemente "ensimismado" y un oficio "conectado" con las necesidades de diversas instituciones y actores sociales, pero con dificultades para propiciar mayores grados de autonomía (Blois, 2013b; Miglievich, 1999).

\footnotetext{
u ONG. Tal iniciativa, además de reforzar sus ingresos, los relaciona y conecta con audiencias más amplias y con otras lógicas de trabajo. A veces ese tipo de intercambios es estimulado por iniciativas públicas que buscan tender puentes entre la academia y diversas organizaciones o instituciones (ONG, movimientos sociales, agencias estatales, etc.) en torno del análisis y la intervención sobre distintas cuestiones y problemas sociales (seguridad y violencia, ciudad y vivienda, sistema judicial y acceso a la justicia, entre otros). En estos casos, lo que se busca, como nota Perlatto (2013), es evitar que la institucionalización y especialización creciente de la sociología académica lleve a una excesiva "autorreferencia", que confine sus discusiones y hallazgos al universo de pares.
} 


\section{Las dos "culturas sociológicas" y el predominio de la sociología crítica en Brasil y Argentina}

Según pudimos ver, las trayectorias históricas de la sociología en Brasil y Argentina presentan fuertes diferencias. Sin embargo, más allá de ellas, el proceso de crecimiento y diferenciación de las prácticas profesionales de los sociólogos en los últimos años estuvo signado por marcadas similitudes. ¿Cómo dar cuenta de esas convergencias? ¿Cómo explicar que aun con procesos de institucionalización tan diversos el análisis de las prácticas profesionales de los sociólogos en Brasil y Argentina revele semejantes afinidades? ¿Es posible encontrar algún denominador común capaz de echar luz sobre esta cuestión?

En un libro de reciente aparición, François Dubet (2012) distingue dos formas básicas de concebir la utilidad o el papel social de la sociología: la sociología como crítica y la sociología como técnica ${ }^{17}$ Como podrá apreciarse, esta distinción no es nueva, siendo posible rastrearla en los propios orígenes de la disciplina. Por supuesto, se trata de una tipología ideal y, en la práctica, esas concepciones pueden solaparse en un mismo individuo (un sociólogo puede poner en juego diferentes concepciones a lo largo de su trayectoria o, incluso, en un mismo momento de acuerdo con la labor o función que realice). Según creemos, esta tipología ofrece algunas claves interpretativas para explicar la proximidad encontrada entre el caso brasileño y el argentino.

La sociología como crítica, lejos de pensarse como una disciplina, susceptible de reclamar una cierta jurisdicción sobre determinado problema particular, se asume como un ejercicio intelectual con una misión ciertamente ambiciosa: desnaturalizar el mundo social, romper con las ideologías y denunciar las relaciones de poder (Dubet, 2012). La sociología como técnica, por su parte, se propone incrementar el grado de racionalidad de las instituciones y sociedades a partir del asesoramiento a los tomadores de decisión. Su racionalidad, a diferencia de la otra concepción, es ante todo una racionalidad instrumental, ceñida a la consideración de los mejores medios para fines que le vienen dados. Según el modelo clásico ofrecido por Weber, esta concepción busca aportar "claridad" a los actores para volverlos conscientes de los obstáculos, los efectos perversos o las trabas culturales que debilitan sus capacidades de acción (Dubet, 2012).

Ambas concepciones plantean una mirada ciertamente divergente a la hora de pensar el trabajo de los sociólogos y sus posibilidades de profesiona-

${ }^{17}$ En rigor, el autor menciona tres concepciones. La otra es la sociología como intervención. Identificada con la obra de Touraine (y del propio Dubet), esta sociología se propone suscitar la aparición de movimientos sociales. 
lizarse. Para la concepción crítica, trabajar para un cliente o empleador constituye sin más el abandono de la disciplina, la transformación del sociólogo en un "ingeniero social" o "tecnócrata" al servicio de los poderosos y del mantenimiento del orden social. Para la segunda, el desarrollo del sociólogo como un profesional capaz de ofrecer sus servicios a una variada clientela aparece como una posibilidad deseable no sólo para la mejora de la sociedad, que se volvería más racional, sino para el propio desarrollo de la disciplina, que se nutriría con la experiencia de sus practicantes en distintas esferas sociales. Así, si en este caso la sociología se asume como una profesión "como cualquier otra", en el otro se recusa la idea misma de profesión. La sociología, según la mirada crítica, puede ser a lo sumo una profesión académica (sólo la universidad, con la autonomía que ofrece, puede ofrecer un medio de vida legítimo) pero nunca una profesión de consulta, ya que quienes están en condiciones de demandar y emplear sociólogos son los grupos sociales con recursos, precisamente aquellos que no están interesados en cuestionar el orden social vigente.

$\mathrm{Si}$ es posible reconocer en la trayectoria de la disciplina en Brasil y Argentina la presencia de ambas tradiciones, lo cierto es que en ambos casos tendió a predominar la idea de sociología vinculada a la crítica (Rubinich y Langieri, 2007; Ortiz, 1990; Vianna, 2004). Aun cuando hubo quienes defendieron la sociología como una profesión, ${ }^{18}$ capaz de trascender los muros universitarios y ofrecer sus servicios a una variada clientela, esa iniciativa halló por lo general fuertes dificultades y resistencias. Cabe pensar que la tarea no era sencilla en la medida en que, tanto en Brasil como en Argentina, pese a las diferencias que signaron el proceso de institucionalización, la sociología se desarrolló y asentó primeramente en el seno de instituciones académicas (universidades y centros de investigación), favoreciendo su desarrollo inicial como una disciplina "científica", preocupada por legitimar su lugar en el conjunto de la disciplinas universitarias ya reconocidas, y por fundamentar sus derechos a la "investigación básica". Si la vocación de promover los usos sociales de la sociología no estaba ausente, los primeros esfuerzos estuvieron orientados a generar las estructuras que facilitaran la consolidación de la sociología como una disciplina académica (armado de grupos de investigación, formación de académicos, edición de revistas especializadas, establecimiento de vinculaciones con instituciones del exterior, etcétera). La conquista de públicos o clientelas más amplios para la nueva "profesión" sólo podría producirse en una segunda fase. Ello, a diferencia de lo ocurrido con otras profesiones, que surgieron como oficios ocupados en la satisfacción de diversas necesidades sociales y que sólo después y, en el

${ }^{18}$ Entre ellos se destaca el propio Germani (Blois, 2013a). 
marco de un proceso más o menos largo, fueron "normalizando" sus saberes y procedimientos, fundando escuelas o carreras universitarias, y haciéndose un lugar como disciplinas académicas reconocidas. Mientras que en estos casos es posible afirmar que la "aplicación" fue anterior a la formación formal, en el caso de la sociología, tanto en Brasil como en Argentina, se dio un proceso inverso: cabía a los graduados salir a mostrar, a unos actores e instituciones que desconocían lo que la sociología podría hacer por ellos, las bondades de sus servicios. Si semejante empresa no era de por sí sencilla en la medida en que, a diferencia de lo que ocurre con otras profesiones, los resultados propios de la intervención de los sociólogos no siempre son ostensibles o claramente identificables (Legrand y Vrancken, 2004), ${ }^{19}$ los impasses políticos vividos en ambos países a poco de instaladas, los cursos universitarios dificultaron aún más el desarrollo de la sociología como profesión. En efecto, la radicalización política que signó ambos escenarios intelectuales favoreció una concepción que hacía de la sociología una práctica crítica, preocupada por develar y cuestionar la dominación, mucho más que por hacer de la sociología un saber experto a ser ofrecido en el mercado de las profesiones. Si la figura del intelectual público o la del sociólogo como militante político, de gran predicamento en aquellos años, entraron posteriormente en crisis, la crítica a la sociología como técnica mantuvo una persistente vigencia.

Lo anterior, por supuesto, no se dio sin consecuencias. En la medida en que tales concepciones (la sociología como crítica o como técnica) se encarnan en tradiciones, instituciones y espacios de socialización, esas formas de pensar la sociología constituyen verdaderas "culturas disciplinares" con efectos decisivos en la forma en que los sociólogos entienden su oficio y, en consecuencia, actúan (Blois, 2012). Consideremos, a la luz de la distinción entre una "cultura crítica" y una "cultura profesionalista", los tres ejes analizados en la sección anterior.

El predominio de la cultura crítica explica, en buena medida, la relación conflictiva que los espacios de formación y cursos universitarios mantienen con el mercado laboral y los cambios que allí se fueron dando en los últimos años. Si la cultura "profesionalista" alienta una mayor conexión de las carreras con el mercado de trabajo entendiendo que aquello, además de facilitar la inserción de los jóvenes graduados, le da a esos espacios una vinculación más ostensible con los problemas y dilemas que los distintos actores e instituciones sociales deben afrontar (Costa, 1988), la cultura crítica, cuando

${ }^{19}$ Piénsese, por ejemplo, en la conexión más directa que se puede hacer entre la intervención y los resultados en el caso de un médico que alivia un malestar o de un ingeniero que proyecta un puente. 
domina sin contrapesos, censura sin miramientos la "sociología aplicada". Según esta última, el acercamiento o la apertura a lo que ocurre fuera de los muros universitarios es peligroso pues puede conllevar una indeseable "instrumentalización" de la formación de los futuros sociólogos a favor de los intereses del mercado o el Estado. En esas condiciones, a diferencia de lo que ocurre con otras disciplinas o carreras, en las clases o programas, salvo las referencias al mundo académico como destino laboral, no se establecen demasiadas conexiones con lo que sigue a la finalización de los estudios. Al tiempo que eso genera una duradera angustia entre los estudiantes próximos a graduarse ante un futuro incierto, invisibiliza también las labores que buena parte de los graduados realizan cotidianamente.

El predominio de la cultura crítica da cuenta también de la debilidad que, tanto en Brasil como en Argentina, presentan las asociaciones profesionales. En la medida en que la sociología no es — ni puede ser- una profesión de consulta, poco sentido tiene procurar fortalecer sus instituciones según el modelo de las profesiones clásicas. De acuerdo con esta perspectiva, tal preocupación no sería más que un mal confesado "corporativismo" sin otra finalidad que asegurar ciertas posiciones de privilegio para un conjunto de presuntos "sociólogos" más interesados en lograr un buen empleo, que en cuestionar y transformar las relaciones sociales. Para la cultura profesionalista, en contraste, en la medida en que son necesarias ciertas condiciones en la forma de dar respuestas a los pedidos o encargos de los clientes o empleadores, la organización profesional es fundamental. Si la posibilidad de imponer una mirada disciplinaria a la hora de suministrar un servicio profesional cualquiera (aliviar un dolor, aplicar la ley, construir un puente) implica la organización y movilización colectiva de un conjunto de individuos que comparten una misma formación (Freidson, 2009), según esta visión, ello también es necesario cuando se trata de dar respuestas "sociológicas" a problemas sociales. Ahora bien, si definir una jurisdicción o ámbito propio en competencia con otras disciplinas sociales es ya una labor complicada por la superposición de posibles "incumbencias" ${ }^{20}$ el principal escollo de quienes en Brasil y Argentina promovieron el reconocimiento de la sociología como una "profesión" fue lidiar con aquella "cultura crítica" que recusa la idea de sociología como una profesión "como cualquier otra".

La fuerza de la "cultura crítica" echa luz también sobre la forma en que los sociólogos, tanto en Brasil como en Argentina, desarrollan sus activida-

${ }^{20}$ Cabe recordar que la primera ley que regulaba el ejercicio profesional del sociólogo en Brasil fue vetada porque la misma no establecía de manera clara los límites y competencias del sociólogo en relación con otros profesionales vecinos (Moraes Filho, 1966). 
des cuando se insertan en una esfera o institución no académica. Esa forma, según vimos, está signada por una profunda debilidad. Mientras que para la cultura profesionalista volcar la actividad sociológica hacia el asesoramiento de actores o instituciones de diverso tipo no hace — ni debería hacer- del sociólogo un individuo sin margen de maniobra que debe asumir la realización de sus encargos en las condiciones y ritmos por ellos fijadas; en contraste, para la concepción crítica, en su versión más extrema, cuando un sociólogo trabaja para un cliente o empleador deviene un "mercenario". Trabajar para alguien es, de modo inmediato, asumir una posición "servil".

En este caso, lo que la sociología de las profesiones, en sus más distintas versiones (Dubar y Tripier, 1999), le ha reconocido a las profesiones: la posibilidad de mantener frente a las demandas de sus clientelas una cierta independencia de criterio para definir la forma en que satisfacen esas demandas y se encara el trabajo, no aparece como posibilidad para los propios sociólogos. La posición de un médico o de un ingeniero, que no toman en cuenta las opiniones de su paciente o cliente profano a la hora de fijar sus diagnósticos o estrategias, no es pensable para el caso de los sociólogos. Por el contrario, según la visión crítica, quedan presos de la lógica del mercado o de la organización burocrática donde el que paga los servicios impone los criterios a partir de los cuales se realiza el trabajo (Freidson, 2009).

Se entienden, entonces, las tensiones y el malestar de los sociólogos y cientistas sociales brasileños y argentinos que, socializados en esta cultura, deben desarrollar sus labores fuera de la academia. Se entiende también la adaptación pragmática a las necesidades de las distintas esferas donde se insertan —adaptación que, según vimos, "molesta" pero también "libera"¿Qué sentido tiene preocuparse por la imposición de ciertas condiciones a los clientes o empleadores (como el reconocimiento de tiempos o plazos mínimos que garanticen ciertos estándares de calidad, la realización de indagaciones de mayor alcance, susceptibles de poner en juego ideas teóricas más complejas, etc.), si en el fondo se considera que lo que se hace no forma parte "realmente" de la sociología? Según Heilbron, la potestad que las profesiones alcanzan en la sociedad descansa, en buena medida, en la creencia de sus miembros en su condición de agentes con un saber particular. Es con base en esa creencia que se legitima la reivindicación de una incumbencia y un estatus privilegiado frente al público lego y a las otras ocupaciones (Heilbron, 1986). Sin ella, la adaptación sin resistencias a los pedidos del cliente o empleador (y la consiguiente dilución de la "profesión" como tal) es ciertamente más probable. 


\section{Consideraciones finales}

Las trayectorias de la sociología en Brasil y Argentina presentan fuertes diferencias. En el primer caso, el proceso de institucionalización estuvo signado por una relativa estabilidad y un desarrollo en el que resaltan las continuidades sobre las rupturas. En contraposición, en Argentina el proceso fue mucho más accidentado y discontinuo. Lo anterior, según vimos, estuvo fuertemente condicionado por el tipo de vínculo con el Estado (y las élites que lo controlaron) que los sociólogos pudieron construir en cada país. Mientras que en Brasil tendió a predominar una relación de apoyo para el surgimiento, la consolidación y expansión de las instituciones de docencia e investigación, en Argentina se afirmó una relación ciertamente más conflictiva en la que los momentos de distanciamiento y mutua ignorancia se alternaron con la pura y simple persecución.

Pese a esas diferencias, según pudimos apreciar en la segunda parte de este trabajo, en los últimos años el proceso de crecimiento y diferenciación de las prácticas profesionales de los sociólogos estuvo signado por fuertes similitudes. Sea que se considere la vinculación que las carreras y los espacios de formación plantean con las prácticas profesionales, sea que se analice el rol e impacto de las instituciones que buscan defender y representar a la sociología como una "profesión", sea que se pondere la relación que los sociólogos entablan con sus diversos clientes o empleadores, las convergencias son bien marcadas.

Tales convergencias, como vimos en la tercera parte, echan raíces en la particular fuerza que la idea de la sociología como crítica tiene en ambos escenarios intelectuales, en detrimento de aquella que hace de la sociología una técnica capaz de fundamentar el ejercicio de una práctica laboral según el modelo de las profesiones de consulta. Ahora bien, en una situación marcada por el desarrollo y la diferenciación de las prácticas profesionales, el predominio de aquella cultura no se da sin consecuencias: si puede inducir una buena dosis de malestar en los sociólogos que deben lidiar con una práctica laboral que no se corresponde con el ideal de sociología en el que fueron formados, ese predominio limita también — según pudimos apreciar- su capacidad a la hora de reivindicar su mirada disciplinaria frente a los públicos y clientelas que los contratan.

Recibido: marzo de 2014

Revisado: abril de 2015

Correspondencia: Rua Hermenegildo de Barros 8/Ap. 502/Santa Teresa/ Rio de Janeiro/CEP: 20241-040/correo electrónico: pedro.blois@gmail.com 


\section{Bibliografía}

Alves, Ana (2007), Objetivação participante. Um estudo sobre a identidade profissional dos sociólogos da cidade do Rio de Janeiro, Rio de Janeiro, UFRJ, tesis de maestría.

Andrade, Maria (2002), A inserção dos cientistas sociais no mercado do trabalho na Bahia, Salvador, UFBA, tesis de maestría.

Barreira, Carlos (2003), A sociología no tempo: memória, imaginação e utopia, São Paulo, Cortez.

Bekerman, Fernanda (2009), "El campo científico argentino en los años de plomo: desplazamientos y reorientación de los recursos”, Sociohistórica, núm. 26.

Blanco, Alejandro (2006), Razón y modernidad. Gino Germani y la sociología en Argentina, Buenos Aires, Siglo XXI.

Blois, Juan (2013a), Las trayectorias de la sociología en Brasil y Argentina y las prácticas profesionales de los sociólogos. Un estudio comparado, Buenos Aires, Informe CLACSO, octubre.

Blois, Juan (2013b), "Entre la autonomía y la heteronomía. Socialización universitaria y prácticas profesionales de los sociólogos en la Argentina”, Revista de Ciencias Políticas y Sociales, año LVIII, núm. 218.

Blois, Juan (2012), Obligados a elegir “entre el sacerdocio y la prostitución”. Socialización universitaria y prácticas profesionales de los sociólogos de la UBA, Buenos Aires, UBA, tesis de doctorado.

Blois, Juan (2009), "Sociología y democracia. La reorganización de la carrera de sociología en la Universidad de Buenos Aires”, Sociohistórica, núm. 26.

Blois, Juan (2008), "Interpretaciones enfrentadas de la historia de la sociología en Argentina. Las lecturas del pasado como disputas del presente", Argumentos, núm. 10.

Blundi, Maria (1997), O financiamento das Ciências Sociais no Rio de Janeiro: o caso da FINEP, Rio de Janeiro, UFRJ, tesis de maestría.

Bonaldi, Pablo (2009), Aprendiendo sociología, Buenos Aires, La Gomera.

Bonelli, Maria (1993), Identidade profissional e mercado de trabalho dos cientistas sociais, Campinas, UNICAMP, tesis de doctorado.

Braga, Eugenio (2011), "Novos elementos para uma sociologia dos cientistas sociais. A situação ocupacional dos egressos", Revista Brasileira de Ciências Sociais, vol. 26, núm. 76.

Braga, Eugenio (2009), "Cientistas sociais extra-universitarios: identidade profissional no mercado da pesquisa”, Estudos de Sociologia, vol. 14, núm. 26.

Braga, Gabrielle (no publicado), Formação em Ciências Sociais: de estudantes a profissionais, Rio de Janeiro, IUPERJ.

Brunner, José y Alicia Barrios (1987), Inquisición, mercado y filantropía, Santiago, Flacso.

Burawoy, Micharl (2005), "For Public Sociology", American Sociological Review, vol. 70 .

Carvalho, Lejeune y Sérgio Mattos (2005), Sociólogos \& sociologia. Historia das suas entidades no Brasil e no mundo, São Paulo, Garibaldi. 
Carvalho, Maria (2007), "Temas sobre a organização dos intelectuais no Brasil", RBCS, vol. 22, núm. 65 .

Costa, Fernando (1988), "Cultura profissional dos sociólogos", Sociología, Problemas y Prácticas, núm. 5.

Delich, Francisco (1977), Crítica y autocrítica de la razón extraviada, Buenos Aires, El Cid Editor.

Domingues, José (2003), Do Ocidente à modernidade. Intelectuais e mudança social, Rio de Janeiro, Civilização Brasileira.

Dubar, Claude y Pierre Tripier (1999), Sociologie des professions, París, Armand Colin.

Dubet, François (2012), ¿Para qué sirve realmente un sociólogo?, Buenos Aires, Siglo XXI.

Durand, José (1984), “A mal-assumida profissão de sociólogo”, Revista de Administração de Empresas, vol. 24, núm. 3.

Freidson, Eliot (2009), Profissão médica, São Paulo, UNESP.

García Bouza, Jorge y Eliseo Verón (1967), "Epílogo a uma crónica: la situación de la sociología en Argentina", Revista Latinoamericana de Sociología, vol. 3, núm. 1.

Germani, Ana (2004), Gino Germani. Del antifascismo a la sociología, Buenos Aires, Taurus.

Gomes de Melo, Eduardo (2005), As práticas profissionais do sociólogo como representações sociais dos alunos de ciências sociais da UFPR, Curitiba, UFPR, tesis de maestría.

Heilbron, Johann (1986), "La professionnalisation comme concept sociologique et comme stratégie des sociologues", en AAVV, Historiens et sociologues aujourd'hui, París, CNRS.

Jackson, Luiz y Alejandro Blanco (2014), Sociologia no espelho, São Paulo, Editora 34.

Keinert, Fabio (2010), Cientistas sociais entre ciência e política (Brasil, 1968-1985), São Paulo, USP, tesis de doctorado.

Kreimer, Pablo y Alejandro Blanco (2008), "Sociologie et démocratie? Un panorama de la discipline en Argentine entre 1983 et 2007”, Sociologies Pratiques, núm. 16.

Lahuerta, Milton (2001), "Intelectuais e resistência democrática: vida académica, marxismo e política no Brasil", Cad. Ael., vol. 8, núms. 14-15.

Legrand, Monique y Didier Vrancken (2004), L'expertise du sociologue, París, L'Harmattan.

Leite, Ana (2003), "Os cientistas sociais do Rio do Janeiro e suas opções profissionais nos anos 90", Campinas, XI Congresso Brasileiro de Sociología.

Liedke Filho, Enno (1990), "Sociologia e sociedade. Brasil e Argentina (1954-1984)", Cadernos de Sociologia, núm. 2.

Limongi, Fernando (1989), "Mentores e clientelas da Universidade de São Paulo", en Sérgio Miceli (org.), História das ciências sociais no Brasil, vol. 1, São Paulo, IDESP.

Lippi, Lucia (1995), “As Ciências Sociais no Rio de Janeiro”, en Sérgio Miceli (org.), História das ciências sociais no Brasil, vol. 2, São Paulo, Sumaré. 
Machuca, Adriana (2008), La identidad profesional de los sociólogos, México, Flacso, tesis de maestría.

Marinho, Marcelo (1987), “A profissionalização da sociologia no Brasill, DADOS, núm. 2.

Massi, Fernanda (1989), "Franceses e norte-americanos nas ciências sociais brasileiras (1930-1960)", en Sérgio Miceli (org.), História das ciências sociais no Brasil, vol. 1, São Paulo, IDESP.

Mejía, Roberto (2008), La sociología en México y su relación con el ámbito laboral. El caso de la UAM, México, Instituto Mora, tesis de maestría.

Miceli, Sérgio (1995), "O cenário institucional das Ciências Sociais no Brasil”, en Sérgio Miceli (org.), História das ciências sociais no Brasil, vol. 2, São Paulo, Sumaré.

Miceli, Sérgio (org.) (1989), História das ciências sociais no Brasil, vol. 1, São Paulo, IDESP.

Miglievich, Adélia (1999), “A sociologia quando 'sai' da universidade: ilustrações para um debate", Cadernos Ceru, núm. 10.

Moraes Filho, Evaristo (1966), "Regulamentação da profissão de sociólogo", Sintese Política Econômica Social, núm. 31.

Noé, Alberto (2005), Utopia y desencanto. Creación e institucionalización de la Carrera de Sociología de la Universidad de Buenos Aires, Buenos Aires, Miño y Dávila.

Ortiz, Renato (1990), "Notas sobre as ciências sociais no Brasil", Novos Estudos, núm. 27.

Pécaut, Daniel (1990), Os intelectuais e a política no Brasil. Entre o povo e a nação, São Paulo, Editora Ática.

Pereyra, Diego (2007), "Cincuenta años de la carrera de Sociología de la UBA. Algunas notas contracelebratorias para repensar la historia de la Sociología en Argentina", Revista Argentina de Sociología, vol. 9.

Perlatto, Fernando (2013), Sociologia pública: imaginação sociológica e problemas públicos, Rio de Janeiro, IESP-UERJ, tesis de doctorado.

Perlatto, Fernando (2010), "Sociologia pública e o Brasil: apontamentos para um debate", Revista de Ciências Humanas, vol. 10, núm. 2.

Piriou, Odile (2006), La face cachée de la sociologie, París, Belin.

Raus, Diego (2007), "La sociología en el 'Proceso"', Sociología en Debate, núm. 1.

Reyna, José (2007), "La institucionalización de las ciencias sociales en México", en Hélgio Trindade (coord.), Las ciencias sociales en América Latina en perspectiva comparada, México, Siglo XXI.

Reynaga Obregón, Sonia (1998), Los futuros sociólogos. Aproximaciones a su formación, representaciones y mercado laboral, México, Fondo Editorial Universitario.

Rubinich, Lucas (1999), "Los sociólogos intelectuales: cuatro notas sobre la sociología en los '60", Apuntes de Investigación, núm. 4.

Rubinich, Lucas y Gastón Beltrán (eds.) (2010), ¿Qué hacen los sociólogos?, Buenos Aires, Aurelia. 
Rubinich, Lucas y Marcelo Langieri (2007), “Introducción”, en AAVV, La sociología ahora, Buenos Aires, Siglo XXI.

Sábato, Hilda (1996), "Sobrevivir en dictadura: las ciencias sociales y la "universidad de las catacumbas"”, en Hugo Quiroga y Carlos Tcach (comps.), A veinte años del golpe, con memoria democrática, Rosario, Homo Sapiens.

Sarlo, Beatriz (2002), La batalla de las ideas, Buenos Aires, Ariel.

Schwartzman, Simon (1995), "Os estudantes de ciências sociais", en Elina Pessanha y Glaucia Villas Boas (orgs.), Ciências Sociais. Ensino e pesquisa na graduação, Rio de Janeiro, Jornada Cultural.

Sidicaro, Ricardo (1993), "Reflexiones sobre la accidentada trayectoria de la sociología en la Argentina", Cuadernos Hispanoamericanos, núms. 517-519.

Steren dos Santos, Tania y Raquel Barreto (2010), "Os egressos de Ciências Sociais de uma universidade pública, na perspectiva da sociologia das profissões", $R e$ vista do $\mathrm{CFCH}$, núm. 2.

Torini, Danilo (2012), Formação e identidade profissional: a trajetória de egressos de Ciências Sociais, São Paulo, USP, tesis de maestría.

Trindade, Hélgio (2007), "Las ciencias sociales en Brasil: fundación, consolidación y expansión", en H. Trindade (coord.), Las ciencias sociales en América Latina en perspectiva comparada, México, Siglo XXI.

Turner, Jonathan (2009), "Contra a sociología pública: será ela a melhor forma de tornar a Sociologia relevante?", Caderno CRH, núm. 56.

Unzué, Martín (2013), “Autonomía, evaluación y políticas públicas. Tendencias y límites en los sistemas de Argentina y Brasil”, en Martín Unzué y Sergio Emiliozzi (comps.), Universidad y políticas públicas. ¿En busca del tiempo perdido?, Buenos Aires, Imago Mundi.

Verón, Eliseo (1974), Imperialismo, lucha de clases y conocimiento: 25 años de sociología en Argentina, Buenos Aires, Tiempo Contemporáneo.

Vianna, Luiz (2004), "A institucionalização das ciências sociais e a reforma social: do pensamento social a agenda americana de pesquisa", en Werneck Vianna, $A$ revolução passiva: iberismo e americanismo no Brasil, Rio de Janeiro, Revan.

\section{Acerca del autor}

Juan Pedro Blois es doctor en ciencias sociales por la Universidad de Buenos Aires (UBA). Es profesor de teoría sociológica de la carrera de sociología de la UBA y del Instituto de Ciencias de la Universidad Nacional de General Sarmiento (Argentina). Actualmente se desempeña como investigador visitante del Instituto de Estudos Sociais e Políticos da Universidade do Estado do Rio de Janeiro, y becario posdoctoral del Conselho Nacional de Desenvolvimento Científico e Tecnológico (Brasil). Sus áreas de interés son sociología del conocimiento y sociología de las profesiones. De sus publicaciones citamos "El mercado de trabajo de los sociólogos en Argentina desde la vuelta de la de- 
mocracia. El caso de los graduados de la UBA", Trabajo y Sociedad, núm. 22, 2014, pp. 103-122; y "Entre la autonomía y la heteronomía. Socialización universitaria y prácticas profesionales de los sociólogos en la Argentina", Revista Mexicana de Ciencias Políticas y Sociales, vol. 58, núm. 218, mayoagosto, 2013, pp. 209-231. 